\title{
Transcatheter Aortic Valve Replacement for Pure Native Aortic Valve Regurgitation: A Systematic Review
}

\author{
Jubo Jiang ${ }^{\mathrm{a}}$ Xianbao Liu ${ }^{\mathrm{a}}$ Yuxin He $\mathrm{H}^{\mathrm{a}}$ Qiyuan Xu $\mathrm{Xifeng}^{\mathrm{a}}$ Qhu \\ Sanjay Jaiswal ${ }^{\mathrm{a}}$ Lihan Wang $^{\mathrm{a}} \mathrm{Po} \mathrm{Hu}^{\mathrm{a}}$ Feng Gao ${ }^{\mathrm{a}}$ Yinghao Sun ${ }^{\mathrm{b}}$ \\ Chunhui Liu ${ }^{\mathrm{a}}$ Xiaoping Lin ${ }^{\mathrm{a}} \quad$ Jie Liang ${ }^{\mathrm{a}}$ Kaida Ren ${ }^{\mathrm{a}} \quad$ Jian'an Wang ${ }^{\mathrm{a}}$ \\ a Department of Cardiology, Second Affiliated Hospital, Zhejiang University School of Medicine, \\ Hangzhou, PR China; ${ }^{\text {b}}$ Department of Cardiology, Guangdong People's Hospital, Guangdong, PR China
}

\section{Keywords}

Transcatheter aortic valve replacement · Aortic regurgitation

\begin{abstract}
Background: Transcatheter aortic valve replacement (TAVR) is a recent and an effective treatment option for high- or extreme-surgical-risk patients with symptomatic severe aortic stenosis. However, pure severe native aortic valve regurgitation (NAVR) without aortic stenosis remains a contraindication to TAVR. The aim of our systemic review analysis was to evaluate TAVR in patients with pure NAVR. Methods: We searched the published articles in the PubMed and Web of Science databases (2002-2017) using the Boolean operators for studies of NAVR patients undergoing TAVR. Reference lists of all returned articles were searched recursively for other relevant citations. Pooled estimates were calculated using a random-effects meta-analysis. Results: Finally, a total of 10 studies were included in this analysis. The CoreValve was more frequently used with a lower rate of device success and a higher rate of residual aortic regurgitation. The new-generation transcatheter heart valves (THVs) performed a sig-
\end{abstract}

\section{KARGER}

(c) 2018 S. Karger AG, Basel

E-Mail karger@karger.com

www.karger.com/crd nificantly higher rate with less residual aortic regurgitation and a success rate close to $100 \%$. The 30 -day all-cause mortality rates ranged from 0 to $30 \%$ with an estimate summary rate of $9 \%\left(95 \% \mathrm{Cl}: 5-15 \% ; I^{2}=33 \%\right)$. Cerebrovascular events, major or life-threatening bleeding, major vascular complications, acute kidney disease, and new permanent pacemaker implantation occurred similarly in both the new- and oldgeneration THV devices. Conclusions: Aortic regurgitation remains a challenging pathology for TAVR. TAVR is a feasible and reasonable option for carefully selected patients with pure aortic regurgitation.

(c) 2018 S. Karger AG, Basel

\section{Introduction}

The very first transcatheter aortic valve replacement (TAVR) procedure was performed in 2002 [1], and this treatment has now been a standard option for high- or extreme-surgical-risk patients with symptomatic severe

Dr. Jubo Jiang and Dr. Xianbao Liu contributed equally to this paper.
Jian'an Wang, $\mathrm{MD}, \mathrm{PhD}$

Department of Cardiology, Second Affiliated Hospital

Zhejiang University School of Medicine

Hangzhou 310009 (PR China)

E-Mail wangjianan111@zju.edu.cn 


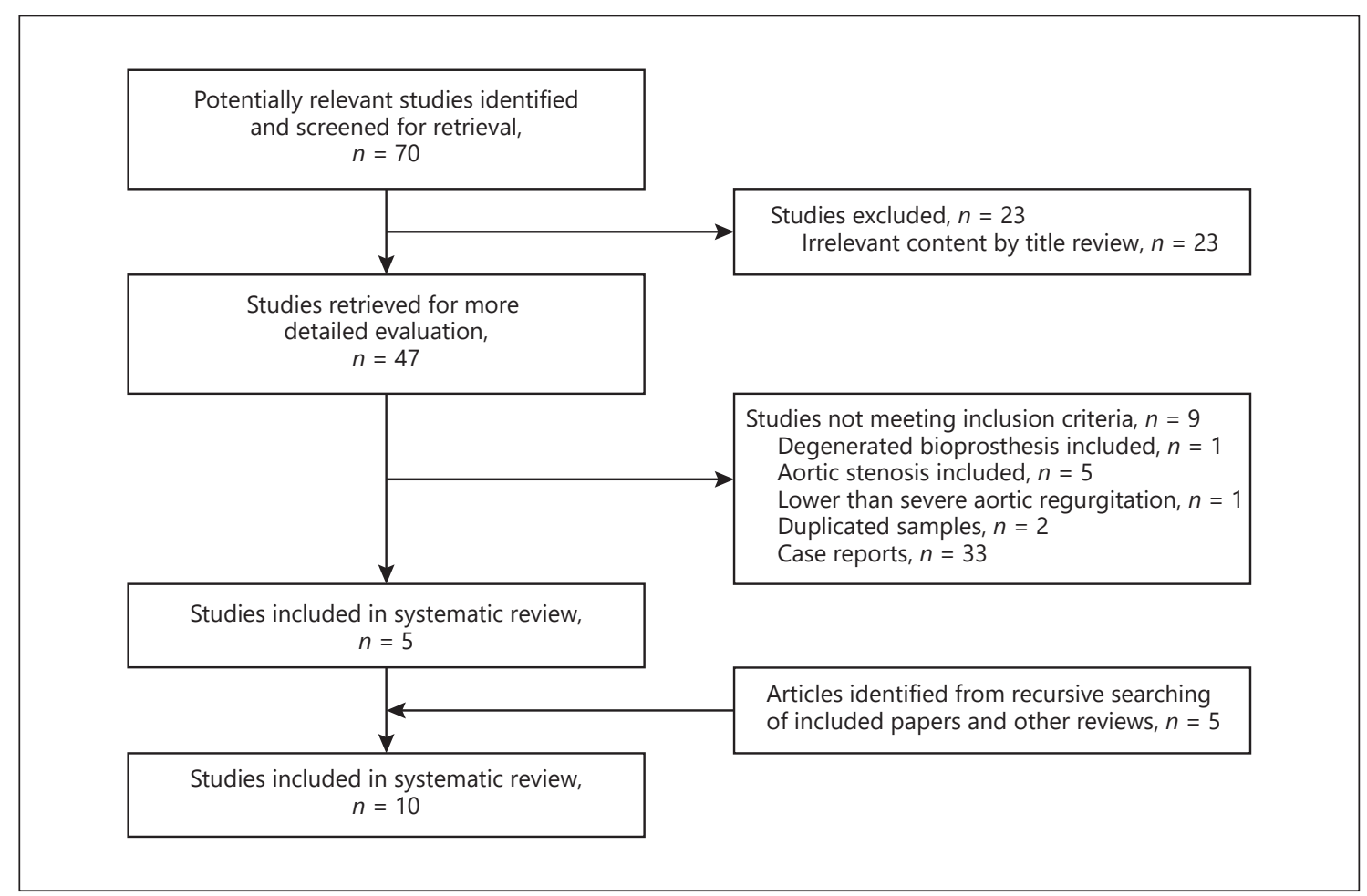

Fig. 1. PRISMA flow diagram depicting the search strategy for the study.

aortic stenosis (AS). Due to fast growing worldwide experience with TAVR, there are more off-label indications for TAVR, such as bicuspid valves, valve-in-valve procedures, TAVR for low-risk patients, etc. [2-4]. Pure severe native aortic valve regurgitation (NAVR) is defined as severe aortic regurgitation (AR) without AS (a peak aortic jet velocity on continuous wave Doppler of $>2.5 \mathrm{~m} / \mathrm{s}$ ) [5]. Many mixed aortic valve disease patients with severe AS and at least moderate AR have been successfully treated with both balloon-expandable and self-expandable TAVR, but pure severe NAVR without AS remains a contraindication to TAVR, and it is not recommended in the guidelines for patients with predominant AR or noncalcified valve [6]. There is limited experience of TAVR in patients with pure severe NAVR. Therefore, we have summarized the available published data, and analyzed the results of TAVR in patients with pure severe NAVR.

\section{Methods}

PubMed and Web of Science databases (2002-2016) were searched using the Boolean operators: (transcatheter aortic valve replacement OR transcatheter aortic valve implantation OR TAVR OR TAVI) AND (aortic regurgitation OR aortic insufficiency OR aortic valve regurgitation OR aortic valve insufficiency OR AR OR AI) from January 2002 to August 2016. The title, abstract, and keywords of the retrieved articles were examined for relevance. Papers were included if they considered an association between TAVR and pure AR. There were no restrictions on the year of publication or language. Full-text versions of all articles were obtained. Case reports and series including patients with failing bioprostheses or AR secondary to other conditions such as endocarditis or aortic dissection were excluded. Articles without any novel data were excluded, such as reviews and comments. Reference lists of all returned articles were searched recursively for other relevant citations.

Data were gathered including first author, year and journal of publication, number of patients, and type of device. Patients' characteristics such as age, sex, New York Heart Association functional class, left ventricular ejection fraction, logistic European System for Cardiac Operative Risk Evaluation score (logistic EuroSCORE), the Society of Thoracic Surgeons score (STS score), and the safety and efficacy outcomes according to Valve Academic Research Consortium 2 criteria were extracted.

During our evaluation, the primary endpoint was all-cause mortality at 30 days, and secondary outcomes were cerebrovascular events, major or life-threatening bleeding, major vascular complications, acute kidney injury ( $\geq$ stage 2 ), moderate to severe residual $\mathrm{AR}$, and permanent pacemaker implantation at 30 days.

Continuous data are reported as mean \pm SD and categorical variables as number of patients and percentage. Random effects meta-analysis was conducted using the Metaprop command, which allows computation of $95 \%$ confidence intervals (CIs) using 
Table 1. Patients' main clinical and procedural characteristics in the studies

\begin{tabular}{|c|c|c|c|c|c|c|c|c|c|c|c|c|c|}
\hline $\begin{array}{l}\text { First author, } \\
\text { year }\end{array}$ & $\begin{array}{l}\text { Patients, } \\
n\end{array}$ & $\begin{array}{l}\text { Age, } \\
\text { years }\end{array}$ & Male & $\begin{array}{l}\text { NYHA } \\
\text { III/IV }\end{array}$ & Etiology (\%) & $\begin{array}{l}\text { Logistic Euro- } \\
\text { SCORE, \% }\end{array}$ & $\begin{array}{l}\text { STS score, } \\
\%\end{array}$ & Device & Access & $\begin{array}{l}\text { Rapid } \\
\text { pacing }\end{array}$ & $\begin{array}{l}\text { Post- } \\
\text { dilation }\end{array}$ & $\begin{array}{l}\text { Second } \\
\text { valve }\end{array}$ & $\begin{array}{l}\text { Device } \\
\text { success }\end{array}$ \\
\hline $\begin{array}{l}\text { Roy [7], } \\
2013\end{array}$ & 43 & $75.3 \pm 8.8$ & $20(47)$ & $42(98)$ & $\begin{array}{l}\text { Degenerative (62.8) } \\
\text { Post-endocarditis (14) } \\
\text { Aortic aneurysm }(9.3) \\
\text { Rheumatoid vasculitis, } \\
\text { Takayasu arteritis (7) } \\
\text { Others }^{\star}(7)\end{array}$ & $26.9 \pm 17.9$ & $10.2 \pm 5.3$ & CoreValve & $\begin{array}{l}\text { Femoral }(81.4) \\
\text { Subclavian }(9.3) \\
\text { Direct aortic }(7.0) \\
\text { Carotid }(2.3)\end{array}$ & $43(100)$ & $4(9)$ & $8(19)$ & $32(74.4)$ \\
\hline Rossi [8], 2014 & 16 & $84 \pm 2.6$ & NR & NR & NR & 33 & NR & CoreValve & NR & NR & NR & $1(6)$ & $13(81)$ \\
\hline $\begin{array}{l}\text { Schlingloff [9], } \\
2014\end{array}$ & 10 & $79 \pm 9$ & $6(10)$ & $9(90)$ & $\begin{array}{l}\text { Degenerative }(80) \\
\text { Post-endocarditis (10) } \\
\text { Aortic aneurysm (10) }\end{array}$ & $28.3 \pm 17.1$ & $6.7 \pm 11.1$ & JenaValve & Apical & 0 & 0 & 0 & $10(100)$ \\
\hline $\begin{array}{l}\text { Seiffert [10], } \\
2014\end{array}$ & 31 & $73.8 \pm 9.1$ & $20(65)$ & $28(90)$ & $\begin{array}{l}\text { Degenerative (48.4) } \\
\text { Annular dilation (19.3) } \\
\text { Post-endocarditis (12.9) } \\
\text { Others }^{*}(19.4)\end{array}$ & $23.6 \pm 14.5$ & $5.4 \pm 3.6$ & JenaValve & Apical & 0 & $2(6)$ & $1(3)$ & $30(97)$ \\
\hline $\begin{array}{l}\text { Testa [11], } \\
2014\end{array}$ & 26 & $73 \pm 10$ & $16(63)$ & $25(95)$ & NR & $24 \pm 8$ & $13.1 \pm 2$ & CoreValve & $\begin{array}{l}\text { Femoral (81) } \\
\text { Subclavian (15) } \\
\text { Direct aortic (4) }\end{array}$ & $26(100)$ & $3(10)$ & $5(19)$ & $20(77)$ \\
\hline $\begin{array}{l}\text { Wendt [12], } \\
2014\end{array}$ & 8 & $72.5 \pm 8.4$ & $5(63)$ & $8(100)$ & $\begin{array}{l}\text { Degenerative }(75) \\
\text { Failed aortic root repair (25) }\end{array}$ & $34.0 \pm 7.9$ & $7.9 \pm 3.4$ & ACURATE TA & Apical & $8(100)$ & $2(25)$ & 0 & $8(100)$ \\
\hline $\begin{array}{l}\text { Munoz [13], } \\
2015\end{array}$ & 10 & $79.2 \pm 4.9$ & NR & NR & NR & $15.3 \pm 8$ & NR & CoreValve & Femoral & NR & $4(40)$ & $1(10)$ & NR \\
\hline $\begin{array}{l}\text { Schofer [14], } \\
2015\end{array}$ & 11 & $74.7 \pm 12.9$ & $4(36)$ & $9(82)$ & $\begin{array}{l}\text { Degenerative (63.6) } \\
\text { Post-endocarditis (9.1) } \\
\text { Others* }(27.3)\end{array}$ & $19.9 \pm 7.1$ & $8.84 \pm 8.9$ & $\begin{array}{l}\text { Direct } \\
\text { Flow }\end{array}$ & Femoral & NR & 0 & 0 & $11(100)$ \\
\hline Zhu [15], 2016 & 33 & $74.2 \pm 5.2$ & $26(79)$ & $27(82)$ & NR & $24.4 \pm 5.1$ & NR & J-Valve & Apical & 0 & 0 & 0 & $31(94)$ \\
\hline $\begin{array}{l}\text { Sawaya [16], } \\
2017\end{array}$ & 78 & $74 \pm 10$ & $46(59)$ & $72(92)$ & $\begin{array}{l}\text { Degenerative (63) } \\
\text { Aortic aneurysm (11) } \\
\text { Post-endocarditis (8) } \\
\text { Rheumatoid vasculitis, } \\
\text { Takayasu arteritis (6) } \\
\text { Others }^{\star}(12)\end{array}$ & $20.4 \pm 11.8$ & $6.7 \pm 4.8$ & $\begin{array}{l}\text { CoreValve (42) } \\
\text { Evolut R (6) } \\
\text { JenaValve (29) } \\
\text { Direct Flow (8) } \\
\text { Lotus (8) } \\
\text { SAPIEN XT (5) } \\
\text { SAPIEN 3 (1) }\end{array}$ & $\begin{array}{l}\text { Femoral (65) } \\
\text { Subclavian (3) } \\
\text { Direct aortic (3) } \\
\text { Apical (29) }\end{array}$ & NR & NR & $13(17)$ & $55(72)$ \\
\hline
\end{tabular}

Values are $n(\%)$ or mean \pm SD unless otherwise indicated. NYHA, New York Heart Association; EuroSCORE, European System for Cardiac Operative Risk Evaluation; STS, Society of Thoracic Surgeons; NR , no record. * Others include post-radiotherapy, trauma, rheumatic disease, and unknown mechanisms.

the score statistic and the exact binomial method and incorporates the Freeman-Tukey double arcsine transformation of proportions. All analyses were performed with Stata statistical software version 12 (StataCorp LP, College Station, TX, USA).

\section{Results}

Finally, a total of 10 studies [7-16] of TAVR were identified in our systematic review (Fig. 1), with 266 patients in total undergoing TAVR. Main clinical outcomes and patient characteristics of all studies are summarized in Table 1. Mean age ranged from 72 to 84 years; mean logistic EuroSCORE ranged from 15.3 to $33 \%$; STS scores were available in 7 studies, with the mean ranging from 5.4 to $13.1 \%$. Nearly half of the patients $(48.1 \%)$ were treated with the Medtronic CoreValve (Medtronic, Minneapolis, MN, USA) which were classified as old-generation transcatheter heart valve (THV) devices whereas the other half underwent TAVR with the new-generation
THV devices such as JenaValve (JenaValve Technology $\mathrm{GmbH}$, Munich, Germany), Lotus Valve System (Boston Scientific, Natick, MA, USA), Direct Flow Medical (DFM) (Direct Flow Medical, Santa Rosa, CA, USA), ACURATE TA (Symetis SA, Ecublens, Switzerland), Evolut R (Medtronic), Edwards Sapien 3 (Edwards Lifesciences, Irvine, CA, USA) and J-Valve (Jiecheng Medical Technology, Suzhou, China). Access was available in 9 studies including transfemoral access in 128 patients (41.2\%), transapical access in 105 patients (42\%), and transcarotid, transsubclavian, or direct aortic access in 17 patients (6.8\%); 29 patients (10.9\%) required a second valve including 24 old-generation THV cases. Device success was reported in 9 studies and ranged from 72 to $100 \%$.

Rates of all-cause mortality at 30 days ranged from 0 to $30 \%$ with a summary estimate rate of $9 \%$ (95\% CI: $5-15 \% ; I^{2}=33 \%$ ) (Fig. 2). Figure 3 shows the secondary outcomes. Stroke or transient ischemic attack (TIA) ranged from 0 to $5 \%$ with a summary estimate of $1 \%(95 \%$ CI: 0-3\%); the rate of major or life-threatening bleeding 


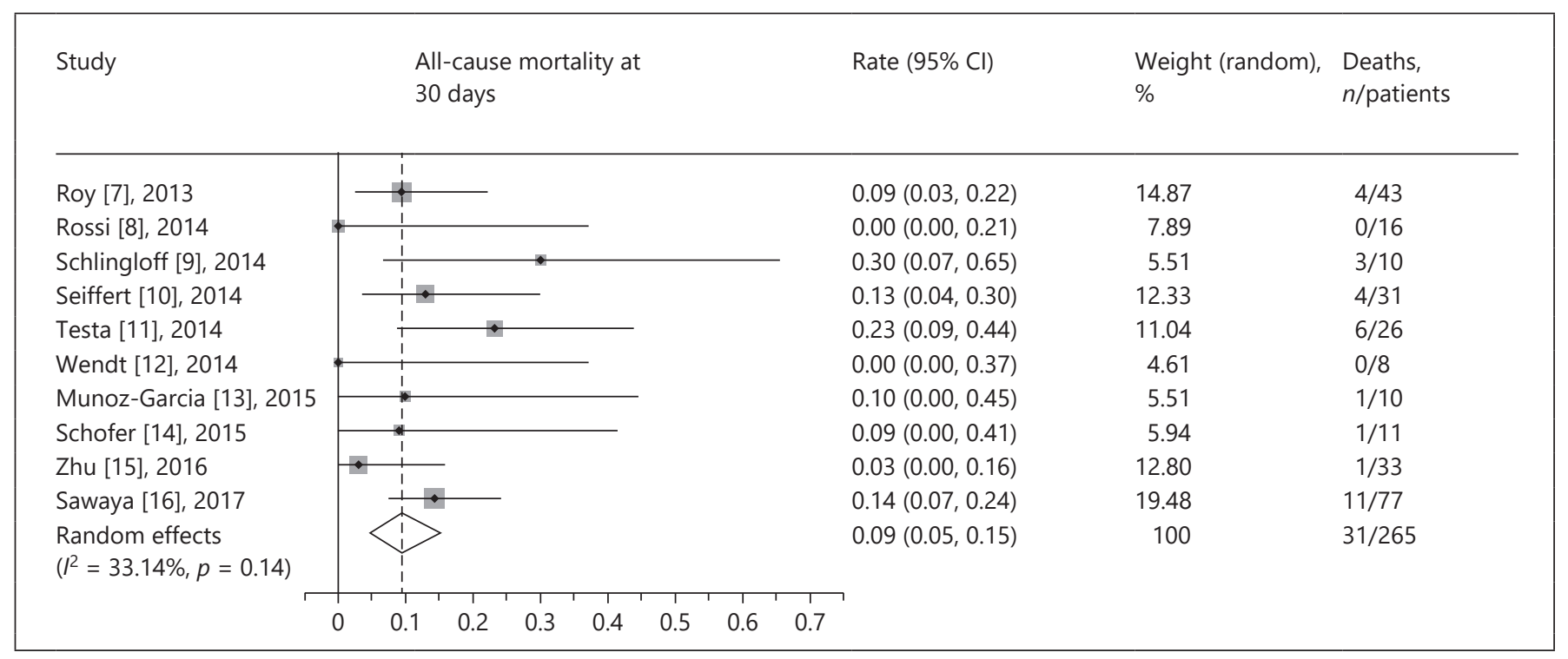

Fig. 2. Forest plot showing the individual and pooled event rates for all-cause mortality at 30 days after TAVR. For each individual study, the forest plot shows the event rate and respective $95 \%$ confidence interval (CI) (horizontal lines). The size of the grey squares is proportional to the weight assigned to the study in the pooled estimate using a random-effects model. The blue diamond below the studies represents the effect estimate derived from the metaanalysis, with the center and the vertical line (maroon) indicating the pooled event rate and the left and the right ends showing the 95\% CI. The central vertical line (red) represents the event rate of $0 \% . I^{2}$ statistics describe the percentage of the variability in effect estimates that is due to heterogeneity rather than chance.

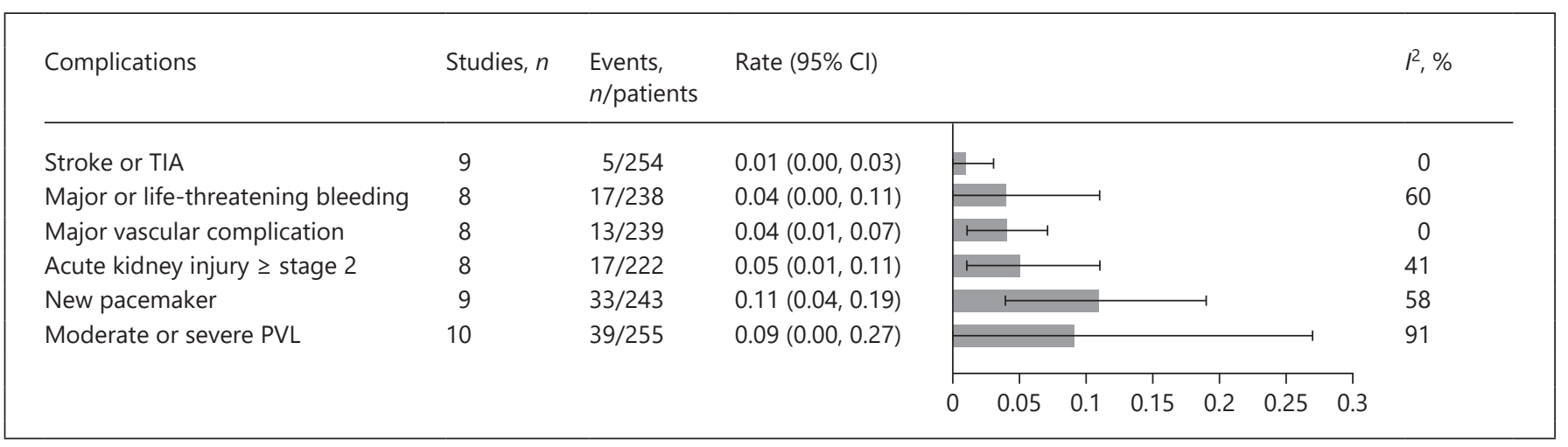

Fig. 3. Meta-analysis of secondary outcomes. Bar graphs show the pooled event rate and relative 95\% confidence interval (CI) (horizontal lines) for the secondary outcomes. Explanation of the $I^{2}$ statistic is reported in the legend of Figure 2. TIA, transient ischemic attack; PVL, paravalvular leak.

and major vascular complications was $4 \%(95 \%$ CI: $\left.0-11 \% ; I^{2}=60 \%\right)$ and $4 \%\left(95 \%\right.$ CI: $\left.1-7 \% ; I^{2}=0 \%\right)$, respectively. Stage 2 or 3 acute kidney injury occurred in $5 \%$ of patients (95\% CI: $\left.1-11 \% ; I^{2}=41 \%\right)$. Rates of new permanent pacemaker implantation after TAVR ranged from 0 to $44 \%$ with a summary estimate rate of $11 \%$ (95\% CI: $\left.4-19 \% ; I^{2}=58 \%\right)$. Moderate to severe residual AR ranged from 0 to $88 \%$ (95\% CI: $\left.0-27 \% ; I^{2}=91 \%\right)$.
Compared to the old-generation THV devices, newergeneration THV devices (Evolut R, SAPIEN 3, Lotus Valve System, Direct Flow, ACURATE TA, JenaValve, and J-Valve) had a higher device success ( 95 vs. $71 \%, p=$ $0.000)$ and a lower incidence of moderate to severe AR (0 vs. $28 \% ; p=0.031$ ) (Fig. 4). All-cause mortality at 30 days ( 7 vs. $12 \% ; p=0.484$ ), stroke or TIA ( 0 vs. $2 \% ; p=0.291$ ), major or life-threatening bleeding ( 1 vs. $11 \% ; p=0.080$ ), 


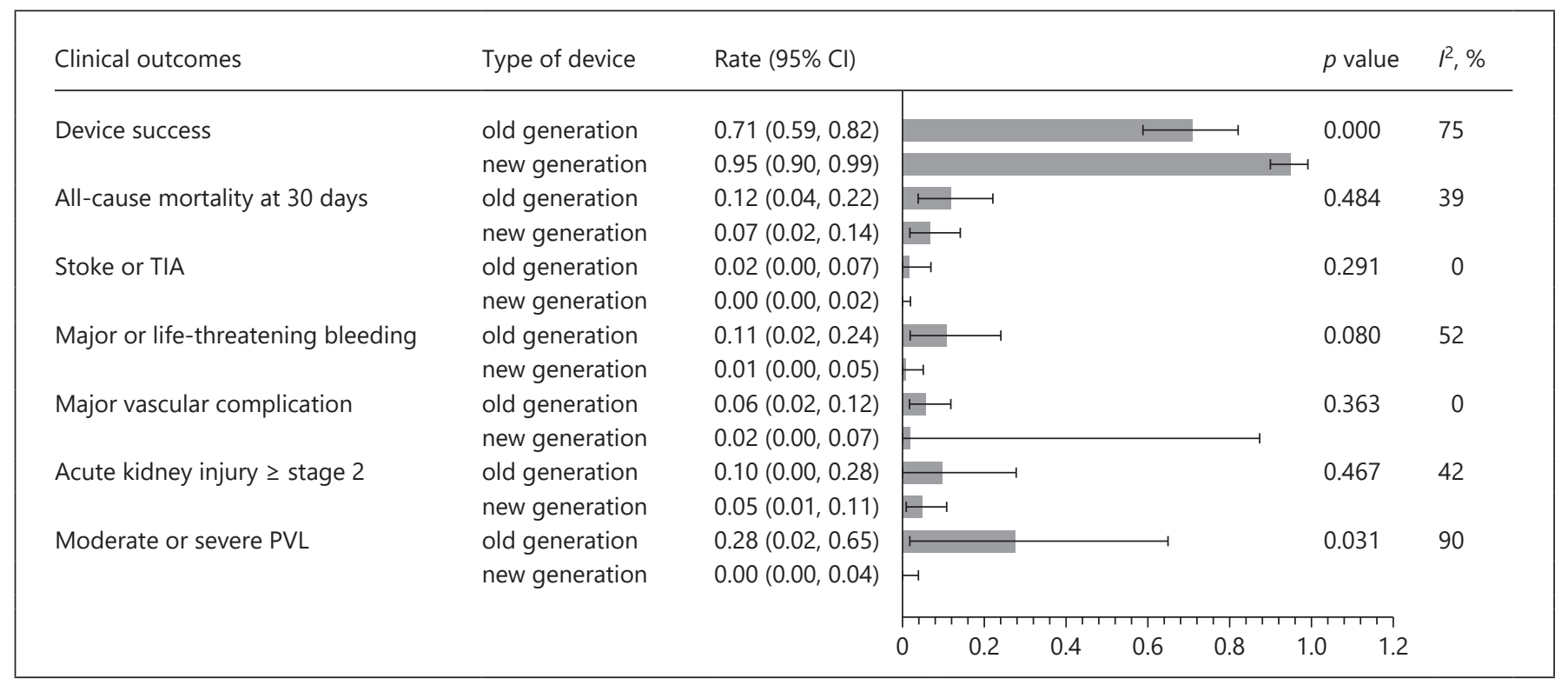

Fig. 4. Comparison of clinical outcomes between old- and new-generation THV devices. Bar graphs show the pooled event rate and relative $95 \%$ confidence interval (CI) (horizontal lines) for the clinical outcomes. Explanation of the $I^{2}$ statistic is reported in the legend of Figure 2. TIA, transient ischemic attack; PVL, paravalvular leak.

major vascular complications ( 2 vs. $6 \% ; p=0.363)$, and acute kidney injury ( 5 vs. $10 \%$; $p=0.467$ ) occurred similarly in both the new- and old-generation groups.

\section{Discussion}

The present studies showed that the etiology of regurgitation was degenerative in the majority of patients but also included annular dilation, previous endocarditis, rheumatic disease, arteritis, or postradiation valve disease. Due to diverse etiologies, patients with AR have a more complex and variable anatomy. They often have a dilated aortic root, a dilated ascending aorta, and an elliptical annulus. Further, the lack of calcification of native aortic cusps and the large annular anatomy contribute to increase the risk of inadequate anchoring, prosthesis dislodgment, and residual paravalvular leak (PVL), so the complex and variable anatomy make transcatheter therapies more challenging. The features of the available THVs in TAVR for pure AR are reviewed in Table 2.

Edwards Sapien prosthesis and CoreValve prosthesis are two typical first-generation TAVR devices. The experience of Edwards Sapien for pure AR is limited. D'Ancona et al. [17] reported the implantation of an Edwards Sapien XT employing substantial oversizing to maximize radial strength and optimize anchoring within the aortic unit (a $29-\mathrm{mm}$ valve within a 21-mm annulus), and also used an overfilled balloon (filled with $35 \mathrm{~mL}$ of contrast instead of the standard $33.5 \mathrm{~mL}$ ). These strategies may lead to a significant risk for annular rupture or incomplete valve expansion. Another challenge is the migration of prosthesis without the resistance of valvular calcification due to higher pressure of the left ventricle when the valve orifice is occluded by dilated balloon. To solve the anchoring problem of the Edwards Sapien, the Helio docking system (Edwards Lifesciences) was investigated, which was placed in the aortic root behind the native leaflets providing secure fixation. The current iteration of the device has evolved into a fully transfemoral approach [18].

Compared to the Edwards Sapien prosthesis, the CoreValve prosthesis is larger with a different anchoring mechanism. Its additional anchorage of the valve stent in the left ventricular outflow tract and ascending aorta may offer additional anchoring force and sufficient stability. Furthermore, the self-expanding valves have the ability to significantly oversize the prosthesis with less risk of damage to the native annulus. Therefore, the CoreValve seems more suitable for the treatment of pure NAVR. Largescale applications of CoreValve were reported by Roy et al. [7] and Testa et al. [11]. They chose $10-20 \%$ oversized 
Table 2. Transcatheter heart valves for pure aortic regurgitation

\begin{tabular}{|c|c|c|c|c|c|c|c|c|c|}
\hline & $\begin{array}{l}\text { Edwards } \\
\text { Sapien }\end{array}$ & CoreValve & Evolute R & $\begin{array}{l}\text { Direct } \\
\text { Flow }\end{array}$ & Lotus & ACURATE & Engager & JenaValve & J-Valve \\
\hline Anchoring site & annulus & $\begin{array}{l}\text { annulus; } \\
\text { ascending } \\
\text { aorta }\end{array}$ & $\begin{array}{l}\text { annulus; } \\
\text { ascending } \\
\text { aorta }\end{array}$ & annulus & annulus & $\begin{array}{l}\text { annulus; } \\
\text { ascending } \\
\text { aorta }\end{array}$ & $\begin{array}{l}\text { annulus; } \\
\text { leaflets }\end{array}$ & $\begin{array}{l}\text { annulus; } \\
\text { leaflets }\end{array}$ & $\begin{array}{l}\text { annulus; } \\
\text { leaflets }\end{array}$ \\
\hline Self-position & - & - & - & + & - & + & + & + & + \\
\hline Repositionable & - & - & partially & fully & fully & partially & - & - & - \\
\hline Oversize & + & + & + & + & + & + & - & - & - \\
\hline Rapid pacing & + & + & + & - & - & - & - & - & - \\
\hline
\end{tabular}

Edwards Sapien (Edwards Lifesciences, USA), CoreValve (Medtronic, Minneapolis, MN, USA), Evolut R (Medtronic, Minneapolis, MN, USA), Direct Flow Medical (Direct Flow Medical, Santa Rosa, CA, USA), Lotus valve (Boston Scientific, Marlborough, MA, USA), ACURATE (Symetis SA, Ecublens, Switzerland), Engager (Medtronic, Minneapolis, MN, USA), JenaValve (JenaValve Technology GmbH, Munich, Germany), J-Valve (Jiecheng Medical Technology, Suzhou, China). +, yes; -, no.

prosthesis with respect to the annulus perimeter, but still showed high rates of valve-in-valve procedures (18.6 and $19.2 \%$, respectively) and residual AR (20.9 and 23\%, respectively). One reason may be lack of valvular calcification leading to reduced fixation of the lower part of the valve frame at the annulus during deployment, resulting in malposition. Another reason may be the regurgitant jet increasing movement of the valve prosthesis, so rapid pacing is required. Yet another reason is the dilated aortic root and ascending aorta related to insufficient oversizing. Notably, as Testa et al. [11] reported, the need for permanent pacemaker implantation was lower than in conventional TAVR patients with the CoreValve [19], due to larger annulus and left ventricle sizes reducing the compression of atrioventricular conduction.

To overcome the aforementioned problem of high rates of valve-in-valve procedures and residual AR, THVs that can be retrieved and repositioned have been designed. Evolut R (Medtronic) is the successor of the CoreValve, with an attractive advancement whereby the prosthesis can be partially recaptured and repositioned or removed, if needed. Foerst [20] reported a case in which Evolut $\mathrm{R}$ was performed, and the result was acceptable though the valve considerably migrated into the left ventricle, with a mild residual PVL. Taking repositioning a step further, the inflatable DFM and the mechanical expandable Lotus were designed. Both valves have some of the advantages of pure AR. First, valveoperating function during positioning improves hemodynamic stability. Second, the prosthesis can be repositioned and fully retrieved if operators are not satisfied with the position, stability of anchoring, or significant residual AR. Schofer et al. [14] reported the largest use of
DFM for pure severe AR in 11 high-risk patients. No residual moderate or severe AR and valve-in-valve procedures were observed, although 1 patient needed further surgical valve replacement because of an unstable prosthesis. Anchoring DFM does not necessarily need valvular calcification but needs adequate oversizing of at least $2 \mathrm{~mm}$ compared to the size of the native annulus. However, rapid pacing is needed to decrease the regurgitant jet when it is difficult to pull the valve up to the annulus. The DFM incorporates aortic and ventricular inflatable bladders as self-seating geometry to assist in positioning and anchoring. The experience with Lotus is limited, but the results reported by Wohrle et al. [21] and Saraf et al. [22] were favorable. Another retrievable and repositionable THV is the ACURATE TA, which has a self-expandable nitinol stent consisting of upper and lower crowns that can correct valve fixation in a subcoronary and supra-annular position. The unique structure offers tactile feedback and self-positioning at a supra-annular level. Three additional stabilizations can orient the bioprosthesis in the ascending aorta, and the hourglass design (a narrower waist) can cover the annulus to facilitate coaxial alignment. Wendt et al. [12] evaluated ACURATE TA in 8 patients with noncalcified AR without significant PVL and valve-in-valve procedures.

The abovementioned THVs are all designed for calcified aortic valves. Several THVs are currently available with a different anchoring mechanism that does not need valvular calcification, such as the JenaValve, Engager valve, and J-Valve. The JenaValve has a feeler-guided positioning and a clip fixation mechanism of the native aortic valve leaflets, which ensure anatomically correct and secure implantation even in the absence of valvular cal- 
cification [23]. Moreover, it does not need oversizing to reduce the risk of annular dilation or rupture during TAVR. Also, no rapid pacing is needed during valve deployment because of beating-heart implantation, hence it is safer in patients with hemodynamic insufficiency or depressed left ventricular function. The rare need for valvuloplasty or post-dilation can also alleviate the risk for conduction disturbances and annular rupture. The apparent difference from the CoreValve is that the prosthesis is fixed on the leaflets with no influence of dilated ascending aorta. Seiffert et al. [10] reported the largest usage in 31 high-risk patients with pure $\mathrm{AR}$, and the clinical outcomes compared favorably with published trials and registries for TAVR in the treatment of AS. Because of successful implantations in patients with AR, the JenaValve has already received the Conformité Européene (CE) mark approval for the treatment of AR, and it is the only transcatheter valve CE marked for both AS and AR. However, the feelers and the frame of the JenaValve are integrated by a fixed connection. Therefore, the position of the valve can only be adjusted to a limited extent once the three arms have been placed into the aortic sinuses. This may result in inadequate alignment and suboptimal positioning due to a difficult anatomy (e.g., horizontal aorta) or insufficient imaging, causing significant PVL or even dislodgment of the prosthesis. Compared to a balloon-expandable THV, the JenaValve has less radial force leading to severe PVL in patients with heterogeneous calcification. This was observed in 1 patient with incomplete stent expansion, who required valve-in-valve implantation. The Engager valve incorporates a shaped main frame and a support frame, which has three control arms that are placed into the sinus of the aortic root to achieve an anatomically correct position [24]. As with the JenaValve, the connection between the main frame and the support frame is fixed. Experience with Engager valve in pure AR is limited to an isolated report [25]. The $\mathrm{J}$-Valve system is completely designed by a Chinese company, with a similar design to the JenaValve and the Engager valve. The movable connection between the clasper and the support frame is a unique design, providing fine positioning and active fixation to the leaflets. Therefore, the prosthesis can be deployed in a perfect position coaxially with the left ventricular outflow tract even with difficult anatomy. The recent report by Zhu et al. [15] showed favorable procedural outcomes in a single patient with moderate residual AR. The aforementioned three types of THVs have shown promising results, but these valves were transapically implanted, which may increase the risk of morbidity in high-risk or inoperable patients, especially those with a dilated left ventricle or left ventricular assist device. Heterogeneous calcification patterns may be unsuitable for these THVs due to their lower radial force.

Another concern is that a proportion of AR is caused by annular dilation due to aortic aneurysm, bicuspid aortic valve, Marfan syndrome, etc. In general, thoracic aortic aneurysms expand by about $0.3 \mathrm{~cm}$ per year [26]. Because of the added risk of aortic dissection, a surgical indication should be considered for aortic root dilation $>55$ $\mathrm{mm}$ irrespective of the severity of $\mathrm{AR}$, and even smaller diameters $(<45 \mathrm{~mm})$ in patients with high risk factors for dissection, such as a rapid increase in aortic diameter (5 mm per year). Therefore, the aortic diameter may still increase after TAVR in cases of aortic aneurysm, bicuspid aortic valve, Marfan syndrome, etc. According to the experience of Roy et al. [7], patients with an ascending aorta aneurysm had a poor response to treatment with TAVR ( 3 out of 4 patients died within 6 months of treatment). TAVR was ineffective in altering the prognosis of these patients, and aneurysmal dilation may be a contraindication to TAVR in patients with pure AR.

\section{Study Limitations}

First, the small number of studies and included patients limit the validity of our findings. Second, included studies were different in relation to TAVR devices used, access, technique, and outcome definition, making a comparison across reports impossible. Third, incomplete data, especially for baseline and patient characteristics, were frequent across studies. Fourth, our data were the periprocedural outcomes, and longer-term follow-up is necessary to evaluate the efficacy of TAVR for AR. Fifth, the results of the meta-analysis should be carefully interpreted for the majority of TAVR in isolated AR because of low statistical power. Finally, there is not enough information available related to patients with AR due to aortic root dilation.

\section{Conclusions}

Promising procedural and early results of TAVR have been reported in a small sample of pure AR patients, but larger patient numbers, longer-term follow-up, and headto-head comparison with surgical aortic valve replacement (SAVR) are needed before drawing final conclusions. The implications for TAVR in terms of device design, procedural consideration (valve sizing, access), hemodynamic results (PVL), and clinical outcomes re- 
quire further investigation. The association of AR with progressive aortic dilation poses a particular concern for the durability of a conventional TAVR procedure. A minimally invasive (via transfemoral access), accurately positioned, fully repositioned, effectively sealed, suitable for enlarged annuli, and durable TAVR device is required for an unmet clinical need of high-surgical-risk patients with pure NVAR.

\section{Acknowledgments}

This work was supported by Zhejiang Province Science and Technology Department Major Scientific and Technological Projects of major social programs (2015C03028).

\section{Disclosure Statement}

All authors declare that they have no conflicts of interest to disclose.

\section{References}

1 Cribier A, Eltchaninoff $\mathrm{H}$, Bash A, Borenstein N, Tron C, Bauer F, Derumeaux G, Anselme F, Laborde F, Leon MB: Percutaneous transcatheter implantation of an aortic valve prosthesis for calcific aortic stenosis: first human case description. Circulation 2002;106:30063008.

2 Dvir D, Webb JG, Bleiziffer S, Pasic M, Waksman R, Kodali S, Barbanti M, Latib A, Schaefer U, Rodes-Cabau J, Treede H, Piazza N, Hildick-Smith D, Himbert D, Walther T, Hengstenberg C, Nissen H, Bekeredjian R, Presbitero P, Ferrari E, Segev A, de Weger A, Windecker S, Moat NE, Napodano M, Wilbring M, Cerillo AG, Brecker S, Tchetche D, Lefevre T, De Marco F, Fiorina C, Petronio AS, Teles RC, Testa L, Laborde JC, Leon MB, Kornowski R; Valve-in-Valve International Data Registry I: Transcatheter aortic valve implantation in failed bioprosthetic surgical valves. JAMA 2014;312:162-170.

3 Mylotte D, Lefevre T, Sondergaard L, Watanabe Y, Modine T, Dvir D, Bosmans J, Tchetche D, Kornowski R, Sinning JM, TheriaultLauzier P, O'Sullivan CJ, Barbanti M, Debry N, Buithieu J, Codner P, Dorfmeister M, Martucci G, Nickenig G, Wenaweser P, Tamburino $\mathrm{C}$, Grube E, Webb JG, Windecker S, Lange R, Piazza N: Transcatheter aortic valve replacement in bicuspid aortic valve disease. J Am Coll Cardiol 2014;64:2330-2339.

4 Thyregod HG, Steinbruchel DA, Ihlemann N, Nissen H, Kjeldsen BJ, Petursson P, Chang Y, Franzen OW, Engstrom T, Clemmensen P, Hansen PB, Andersen LW, Olsen PS, Sondergaard L: Transcatheter versus surgical aortic valve replacement in patients with severe aortic valve stenosis: 1-year results from the allcomers NOTION randomized clinical trial. J Am Coll Cardiol 2015;65:2184-2194.

5 Baumgartner H, Hung J, Bermejo J, Chambers JB, Evangelista A, Griffin BP, Iung B, Otto CM, Pellikka PA, Quinones M; EAE/ ASE: Echocardiographic assessment of valve stenosis: EAE/ASE recommendations for clinical practice. Eur J Echocardiogr 2009;10: $1-25$.

6 Vahanian A, Alfieri O, Andreotti F, Antunes MJ, Baron-Esquivias G, Baumgartner $\mathrm{H}$, Borger MA, Carrel TP, De Bonis M, Evange- lista A, Falk V, Lung B, Lancellotti P, Pierard L, Price S, Schafers HJ, Schuler G, Stepinska J, Swedberg K, Takkenberg J, Von Oppell UO, Windecker S, Zamorano JL, Zembala M: ESC Committee for Practice Guidelines (CPG); , Joint Task Force on the Management of Valvular Heart Disease of the European Society of Cardiology (ESC), European Association for Cardio-Thoracic Surgery (EACTS): Guidelines on the management of valvular heart disease (version 2012): the Joint Task Force on the Management of Valvular Heart Disease of the European Society of Cardiology (ESC) and the European Association for Cardio-Thoracic Surgery (EACTS). Eur J Cardiothorac Surg 2012;42:S1-S44.

7 Roy DA, Schaefer U, Guetta V, Hildick-Smith D, Mollmann H, Dumonteil N, Modine T, Bosmans J, Petronio AS, Moat N, Linke A, Moris C, Champagnac D, Parma R, Ochala A, Medvedofsky D, Patterson T, Woitek F, Jahangiri M, Laborde JC, Brecker SJ: Transcatheter aortic valve implantation for pure severe native aortic valve regurgitation. J Am Coll Cardiol 2013;61:1577-1584.

8 Rossi M, Barbaro C, Pagnotta P, Lucarelli C, Mennuni M, Presbitero P: Transcatheter aortic valve implantation in patients with pure severe native aortic regurgitation: results after 3 year of follow-up (abstract). J Am Coll Cardiol 2014;64:B220-B221.

9 SchlingloffF, Schafer U, Frerker C, Schmoeckel M, Bader R: Transcatheter aortic valve implantation of a second-generation valve for pure aortic regurgitation: procedural outcome, haemodynamic data and follow-up. Interact Cardiovasc Thorac Surg 2014;19:388393.

10 Seiffert M, Bader R, Kappert U, Rastan A, Krapf S, Bleiziffer S, Hofmann S, Arnold M, Kallenbach K, Conradi L, Schlingloff F, Wilbring M, Schafer U, Diemert P, Treede H: Initial German experience with transapical implantation of a second-generation transcatheter heart valve for the treatment of aortic regurgitation. JACC Cardiovasc Interv 2014; 7:1168-1174

11 Testa L, Latib A, Rossi ML, De Marco F, De Carlo M, Fiorina C, Oreglia J, Petronio AS, Ettori F, De Servi S, Klugmann S, Ussia GP,
Tamburino C, Panisi P, Brambilla N, Colombo A, Presbitero P, Bedogni F: CoreValve implantation for severe aortic regurgitation: a multicentre registry. EuroIntervention 2014; 10:739-745.

12 Wendt D, Kahlert P, Pasa S, El-Chilali K, AlRashid F, Tsagakis K, Dohle DS, Erbel R, Jakob H, Thielmann M: Transapical transcatheter aortic valve for severe aortic regurgitation: expanding the limits. JACC Cardiovasc Interv 2014;7:1159-1167.

13 Munoz-Garcia E, Munoz-Garcia M, MunozGarcia A, Dominguez-Franco A, JimenezNavarro M, Alonso-Briales J: Safety of transcatheter aortic valve implantation in patients with pure native aortic valve regurgitation (abstract). Eur Heart J 2015;36:793.

14 Schofer J, Nietlispach F, Bijuklic K, Colombo A, Gatto F, De Marco F, Mangieri A, Hansen L, Bruschi G, Ruparelia N, Riess FC, Maisano F, Latib A: Transfemoral implantation of a fully repositionable and retrievable transcatheter valve for noncalcified pure aortic regurgitation. JACC Cardiovasc Interv 2015;8: 1842-1849.

15 Zhu D, Wei L, Cheung A, Guo Y, Chen Y, Zhu L, Liu H, Yang Y, Zhang J, Wang C: Treatment of pure aortic regurgitation using a second-generation transcatheter aortic valve implantation system. J Am Coll Cardiol 2016;67: 2803-2805.

16 Sawaya FJ, Deutsch MA, Seiffert M, Yoon SH, Codner P, Wickramarachchi U, Latib A, Petronio AS, Rodes-Cabau J, Taramasso M, Spaziano M, Bosmans J, Biasco L, Mylotte D, Savontaus $\mathrm{M}$, Gheeraert $\mathrm{P}$, Chan J, Jorgensen TH, Sievert H, Mocetti M, Lefevre T, Maisano F, Mangieri A, Hildick-Smith D, Kornowski R, Makkar R, Bleiziffer S, Sondergaard L, De Backer O: Safety and efficacy of transcatheter aortic valve replacement in the treatment of pure aortic regurgitation in native valves and failing surgical bioprostheses: results from an international registry study. JACC Cardiovasc Interv 2017;10:1048-1056.

17 D’Ancona G, Pasic M, Buz S, Drews T, Dreysse S, Hetzer R, Unbehaun A: TAVI for pure aortic valve insufficiency in a patient with a left ventricular assist device. Ann Thorac Surg 2012;93:e89-e91. 
18 Barbanti M, Ye J, Pasupati S, El-Gamel A, Webb JG: The Helio transcatheter aortic dock for patients with aortic regurgitation. EuroIntervention 2013;9(suppl):S91-S94.

19 Smith CR, Leon MB, Mack MJ, Miller DC, Moses JW, Svensson LG, Tuzcu EM, Webb JG, Fontana GP, Makkar RR, Williams M, Dewey T, Kapadia S, Babaliaros V, Thourani VH, Corso P, Pichard AD, Bavaria JE, Herrmann HC, Akin JJ, Anderson WN, Wang D, Pocock SJ; PARTNER Trial Investigators: Transcatheter versus surgical aortic-valve replacement in high-risk patients. $\mathrm{N}$ Engl J Med 2011;364:2187-2198.

20 Foerst J: Percutaneous repair of left ventricular wire perforation complicating transcatheter aortic valve replacement for aortic regurgitation. JACC Cardiovasc Interv 2016;9: 1410-1411.
21 Wohrle J, Rodewald C, Rottbauer W: Transfemoral aortic valve implantation in pure native aortic valve insufficiency using the repositionable and retrievable lotus valve. Catheter Cardiovasc Interv 2016;87:993-995.

22 Saraf S, Khawaja MZ, Hilling-Smith R, Dooley M, Cockburn J, Trivedi U, Hildick-Smith D: Use of the Lotus transcatheter valve to treat severe native aortic regurgitation. Ann Thorac Surg 2017;103:e305-e307.

23 Lauten A, Ferrari M, Petri A, Ensminger SM, Gummert JF, Boudjemline Y, Schubert H, Schumm J, Hekmat K, Schlosser M, Figulla HR: Experimental evaluation of the JenaClip transcatheter aortic valve. Catheter Cardiovasc Interv 2009;74:514-519.
24 Sundermann SH, Grunenfelder J, Corti R, Rastan AJ, Linke A, Lange R, Falk V, Bleiziffer $S$ : Feasibility of the Engager aortic transcatheter valve system using a flexible over-thewire design. Eur J Cardiothorac Surg 2012; 42:e48-e52.

25 Kiefer P, Seeburger J, Mohr FW, Holzhey DM: Transcatheter aortic valve replacement for isolated aortic valve insufficiency: experience with the Engager valve. J Thorac Cardiovasc Surg 2014;147:e37-e38.

26 Shang EK, Nathan DP, Sprinkle SR, Vigmostad SC, Fairman RM, Bavaria JE, Gorman RC, Gorman JH 3rd, Chandran KB, Jackson BM: Peak wall stress predicts expansion rate in descending thoracic aortic aneurysms. Ann Thorac Surg 2013;95:593-598 